\title{
A 'minimum dose' of lipopolysaccharide required for implantation failure: assessment of its effect on the maternal reproductive organs and interleukin-1 $\alpha$ expression in the \\ mouse
}

\author{
Kaushik Deb, Madan M Chaturvedi ${ }^{1}$ and Yogesh K Jaiswal \\ Molecular Biology and Reproductive Immunology Laboratory, School of Studies in Biochemistry, Jiwaji University, \\ Gwalior- 474011 , India and ${ }^{1}$ Department of Zoology, Delhi University, Delhi-110007, India \\ Correspondence should be addressed to Kaushik Deb, D-4100, Reproductive and Developmental Biology Division, \\ Department of Pediatrics, Medical Center North, Vanderbilt University Medical School, Nashville-37212, Tennessee, USA; \\ Email: kaushik.deb@vanderbilt.edu
}

\begin{abstract}
Genital tract infections caused by gram-negative bacteria induce abortion and are one of the most common complications of human pregnancy. This study was carried out to decipher the mechanism of gram-negative bacterial lipopolysaccharide (LPS)-induced pregnancy loss, using a mouse (Park strain) model. Since many of the biological effects of LPS are mediated by interleukin (IL)-1 $\alpha$, the role of IL-1 $\alpha$ in LPS-induced pregnancy loss was studied. Pregnant female animals were injected intraperitoneally (i.p.) with different doses (1 to $50 \mu \mathrm{g}$ ) of LPS from Salmonella minnesota Re-595, on day 0.5 of pregnancy. We found that $250 \mu \mathrm{g} / \mathrm{kg}$ body weight (i.e. $5 \mu \mathrm{g} /$ female mouse) of LPS when given on day 0.5 of pregnancy was the 'minimum dose' $^{\prime}(\mathrm{MD})$ required to completely inhibit the implantation of the blastocyst in the mouse. The effect of this dose on the pathophysiology of the various reproductive organs (i.e. uterus, ectoplacental cones, developing fetus, ovaries etc.) was assessed on day 14 of pregnancy. The effects of this dose on the level and pattern of expression of the proinflammatory cytokine IL-1 $\alpha$ in the maternal uterine horns and preimplantation stage embryos were studied by RT-PCR. A single dose ( $100 \mathrm{ng} /$ mouse) of recombinant mouse IL-1 $\alpha$ was given i.p. to pregnant females on day 1 of pregnancy to study its effect on implantation. Our results show that treatment of the pregnant animals with LPS may alter cell proliferation and induce leukocyte infiltration, degeneration of luminal glandular epithelium, and hyperplasia in the various reproductive organs, and may also alter both embryonic and uterine IL-1 $\alpha$ expression. IL-1 $\alpha$ administration also caused implantation failure similar to that of LPS. The observations suggest that the determined MD of LPS may alter the expression of developmentally important proinflammatory cytokines such as IL-1 $\alpha$, which could, in turn, inhibit the normal processes of blastocyst implantation. Therefore, it is proposed that the LPS-induced histopathological alterations in the various reproductive organs of pregnant animals could be mediated by IL-1 $\alpha$ and this may be one of the causes of failure of blastocyst implantation in the mouse.

Reproduction (2004) 128 87-97
\end{abstract}

\section{Introduction}

Genital tract infection is one of the major causes of gynecologic morbidity such as infertility, ectopic pregnancy, preterm labor and chronic pelvic pain (Cram et al. 2002). The normal bacterial flora of the vagina possesses a protective effect on their host. Lactobacillus strains taken from normal vaginal flora show antagonistic activity against a variety of bacteria related to vaginal and urinary tract infections (Strus et al. 2002). Any disturbances in the microbial ecosystem of the vagina lead to the colonization of the genitourinary tract with other pathogenic microbes that may lead to vaginitis and other urinary tract infections in humans. Escherichia coli is the most common bacterium isolated; it accounts for about $80 \%$ of community-acquired infections and is associated with an increased incidence of preterm labor and premature rupture of the membranes. $E$. coli has also been found to be responsible for the production of abnormally developed preimplantation embryos in rats (Rupasri et al. 1995). The mouse has been used as a model for studying the mechanism of lipopolysaccharide (LPS)-induced pregnancy loss in a number of studies (Baines et al. 1996). Gram-negative bacterial-induced preterm labor and embryonic loss is accompanied by 
inflammation and infection of the uteroplacental unit. Genital tract infections affect primarily the cervix, uterus, or fallopian tubes and during severe infections one or both ovaries may also be affected.

Endotoxin is the name given to a group of heat-stable LPS molecules present in the cell walls of gram-negative bacteria that possess toxic effects (Burell 1994). These toxins, although intimately associated with the bacterial cell membrane, are constantly shed into the environment of the bacterium much like the daily shedding of the superficial layers of the human skin. Many of the biological effects of LPS are mediated by the proinflammatory cytokines (such as interleukin (IL)-1, IL-6, tumor necrosis factor (TNF) etc.). Several of these cytokines have been implicated in the delicate immune system balances that exist within the feto-maternal interface (Kauma 2000). The presence of cytokines and growth factors in the endometrium and/or embryos and the expression of their corresponding receptors on the implanting blastocyst and/or endometrium, suggest that they may play an important role in the process of development and blastocyst invasion into the endometrium. Previous observations support the involvement of IL-1 in implantation. IL-1 stimulates the production of endometrial leukemia inhibitory factor (LIF), which may be crucial for implantation (Arici et al. 1995). Uterine secretions of many of these cytokines are under the control of ovarian steroids, confirming their close association with a distinct regulatory network that may overlap or compliment the immune system represented by the lympho-hematopoietic cells residing in the uterine endometrium (Paria et al. 2000). This may be a general mechanism for the regulation of early embryonic development and for maintaining a synchrony between the embryo and the uterine preparation for implantation. Any disturbance of this delicate immune balance within the maternal-fetal interface may result in pregnancy loss or other perinatal complications.

During most of the reproductive cycle, the endometrium remains hostile to embryo implantation. It is now clear that there is a brief period during which the endometrium becomes receptive, the so called 'window of receptivity' in each cycle. The endometrium then returns to a non-receptive or refractory period for the remainder of the cycle. Uterine differentiation to support embryo development and implantation is coordinated by ovarian steroids (i.e. progesterone and estrogen) in a spatiotemporal manner (Huet-Hudson \& Dey 1990). In rodents, the first conspicuous sign that the implantation process has been initiated is an increased uterine vascular permeability at the sites of blastocyst apposition (Psychoyos 1973). It has been suggested that the maternal response to blastocyst implantation has a large number of similarities to inflammatory reactions (Mizuno \& Soma 1988). Uterine proinflammatory responses have been suggested to be the result of maternal immunological reactions to the embryo (Ben-Rafael \& Orvieto 1992). The exposure of pregnant female mice to LPS (through i.p. injections) leads to preimplantation embryonic loss (Baines et al. 1996). The endotoxin-induced pregnancy loss may be mediated by the release of various proinflammatory cytokines/growth factors resulting from the activation of lympho-hematopoetic cells of maternal origin. These factors may alter the normal physiology of the reproductive organs of the mother, and may shift the delicate estrogen/progesterone ratio required for the maintenance of successful pregnancy. The present study was designed to determine the 'minimum dose' of LPS required for implantation failure in the mouse and to unravel the effect of LPS on the maternal reproductive organs by performing histopathological analysis. However, the LPS-induced alteration in the level and pattern of expression of IL-1 $\alpha$ in the embryo and the uterus during the implantation period suggests its possible role in early pregnancy loss.

\section{Materials and Methods \\ Animals}

Park strain mice (6-7 weeks of age and weighing $20 \mathrm{~g}$ ) were maintained at $25 \pm 2{ }^{\circ} \mathrm{C}$ in our animal house with a $12 \mathrm{~h}$ light: $12 \mathrm{~h}$ darkness schedule. They were fed a pelleted diet (Amrut India Pvt. Ltd, New Delhi, India) and water available ad libitum. The females were monitored for two consecutive estrous cycles by observing their vaginal smears. They were checked for proestrus and were individually caged overnight with proven fertile males for mating. The females with positive vaginal plugs present the next morning were considered to be on day 0.5 of pregnancy.

\section{Histopathology}

The histopathological analysis of different reproductive organs (i.e. uterus, oviducts and ovaries) was carried out according to a standard procedure. Small portions of recovered uteri, oviducts and ovaries from pregnant animals of each group were dissected out, freed from fat bodies and fixed in buffered formalin for $24 \mathrm{~h}$. Tissues were dehydrated in a graded series of ethanol, cleared in xylene, infiltrated and embedded in paraffin wax at $60^{\circ} \mathrm{C}$. The blocks were sectioned at $8 \mu \mathrm{m}$ using a microtome (Leica, Germany). The tissue sections were stained with hematoxylin and eosin solutions, observed under a microscope (Nikon, Japan) using $10 \times$ and $40 \times$ objectives, and photographed.

The cross-sections of uterus and corpus luteum were checked for the presence of mitotic bodies and macrophages. The number of mitotic bodies per 100 nuclei was counted according to the method of Finn et al. (1995). The distributions of macrophages in uterine, ectoplacental cones (EPCS) and ovarian cross-sections were quantitated by counting their numbers per $40 \times$ view field under the microscope, according to the method of Bagavandoss et al. (1990). 


\section{Pontamine blue reaction}

A pontamine blue reaction test was carried out to assess the status of implantation in pregnant animals (Finn \& McLaren 1967, Psychoyos 1973). The animals were etherized and $0.3 \mathrm{ml} 1 \%$ pontamine blue (Sigma Chemicals Co., USA) in sterile normal saline was injected into each animal through a tail vein. To monitor the implantation sites, the pontamine blue positive/negative sites in the uterine horns were evaluated by performing laparatomy on day 5 of pregnancy.

\section{Determination of the 'minimum dose' of LPS that induces $100 \%$ embryonic loss}

Pregnant females were divided into seven groups of 8 animals each. A single intraperitoneal injection (i.p.) of 1, 2, 4, 5, 10 or $50 \mu \mathrm{g}$ LPS (Salmonella minnesota Re-595, Sigma Chemicals Co.) in $100 \mu \mathrm{l}$ sterile normal saline was given to individual groups on day 0.5 of pregnancy. The control pregnant animals received $100 \mu \mathrm{l}$ normal saline.

LPS-induced failure of blastocyst implantation or fetal death was studied by evaluating the status of the fetuses on day 14 of gestation. The animals were killed by cervical dislocation on day 14 of pregnancy and individual uterine horns and gestational sacs were examined for live (pink, round, uniform with heart beat) and dead (abnormally shaped, hemorrhagic sacs, without heart beat) pups and for resorptions (very small, pale, gray sacs with no discernible fetus). The minimum dose of LPS that completely abrogated pregnancy was considered as the 'minimum dose' (MD) of LPS.

A pontamine blue dye test was also performed on three groups of 4 pregnant females each treated with the vehicle, the lower dose ( $2 \mu \mathrm{g}$ LPS/animal) or the determined MD of LPS, to study the effect of this dose on the initiation of the implantation reaction.

\section{Histopathological analysis of reproductive organs of pregnant animals treated with different doses of LPS on day 0.5 of pregnancy}

The effects of the minimum effective dose and the other lower doses of LPS (given i.p. on day 0.5 of pregnancy) on uterus, placenta, and corpus luteum (CL) of pregnant animals were analyzed by histopathological examinations on day 14 of pregnancy. The pregnant females were divided into four groups of 8 animals each. The pregnant animals of groups 1, 2, 3 and 4 were treated i.p. with different doses of LPS (i.e. 2, 3, 4 or $5 \mu \mathrm{g}$ LPS/animal respectively) on day 0.5 of pregnancy. The control animals of all groups received $100 \mu \mathrm{l}$ sterile normal saline in a similar manner. The animals of all groups were killed by cervical dislocation on day 14 of pregnancy and the reproductive organs were processed immediately as described earlier for histopathological analysis. The cross-sections of different reproductive organs obtained from LPS-treated animals were compared with those of their respective controls.

\section{Recovery of embryos and uterine tissue at different time points}

Female mice (6-7 weeks old, $20 \mathrm{~g})$ were induced to superovulate with i.p. injections of $5 \mathrm{IU}$ each of pregnant mare's serum gonadotropin and human chorionic gonadotropin (Intervet, AB Boxmeer, Holland) at an interval of $48 \mathrm{~h}$. Twenty to twenty-five superovulated pregnant animals/time point were killed by cervical dislocation at different time points through days 0.5 to 4.5 (days 1.5, 2.5, 3.5, 4.0, 4.125, 4.25, 4.33 and 4.42) of pregnancy. About 500 embryos/group were recovered from these animals at each time point/day of pregnancy by flushing the excised reproductive tracts with sterile PBS; the embryos were immediately frozen and stored at $-70^{\circ} \mathrm{C}$ for isolation of total RNA. The uterine horns of the animals were processed immediately for total RNA isolation.

\section{Effect of LPS on expression of IL-1a in embryos and uteri collected at different stages of the preimplantation period of pregnancy}

The effect of LPS on the expression of IL- $1 \alpha$ in embryos and uteri collected at different time points during the preimplantation period (days 1.5, 2.5, 3.5, 4.0, 4.125, $4.25,4.33$ and 4.42 ) of pregnancy was studied by RTPCR. About 20 females at each time point were superovulated to collect 500 embryos/group at each of the above time points of the preimplantation development. The minimum dose of LPS (i.e. $5 \mu \mathrm{g} / \mathrm{animal}$ ) in $100 \mu \mathrm{l}$ sterile normal saline was injected i.p into each pregnant animal on day 0.5 of pregnancy. The control animals received $100 \mu \mathrm{l}$ sterile normal saline in a similar manner. The animals of both groups were killed at narrow intervals of the preimplantation period (i.e. days 1.5, 2.5, $3.5,4.0,4.125,4.25,4.33$ and 4.42 ) of pregnancy to collect the embryos and uterine horns. About 500 embryos were collected at each time point to detect the positive mRNA signals for IL- $1 \alpha$ by RT-PCR.

\section{Preparation of total cellular RNA from embryos collected at different stages of the preimplantation period of pregnancy}

A total of 500 preimplantation stage (2-cell to blastocyst stage) embryos/time point were collected and resuspended in $200 \mu \mathrm{l}$ sterile PBS. The collected embryos were used directly for extraction of total cellular RNA using the High Pure RNA Isolation kit (Boehringer Mannheim, Mannheim, Germany). RNA was isolated according to the instructions provided by the manufacturer and was finally eluted in $60 \mu \mathrm{l}$ of elution buffer. Fifteen microliters of each extract were used for every reaction of RT-PCR. 


\section{Extraction of total cellular RNA from uteri collected at different stages of the preimplantation period of pregnancy}

Total RNA was extracted from uterine horns collected from control and LPS-treated pregnant animals by using the guanidium isothiocyanate-phenol-chloroform method (Chomczynski \& Sacchi 1987). The animals were killed by cervical dislocation and uterine horns were removed quickly, washed with chilled normal saline $(0.9 \% \mathrm{NaCl})$, cleaned, blotted dry and weighed. About $100 \mathrm{mg}$ of the tissue were used for total RNA isolation at each time point. The concentration of total cellular RNA was estimated at $A_{260}\left(1 A_{260}=40 \mu \mathrm{g}\right.$ RNA $)$ and was stored at $-20^{\circ} \mathrm{C}$ for further studies. The quality of the RNA was checked by agarose gel $(1 \%)$ electrophoresis. Ten micrograms of the extracted RNA were used for each reaction of $R T-P C R$.

\section{Reverse transcription-polymerase chain reaction (RT-PCR)}

The RT-PCR was carried out using the Titan One-tube RTPCR System (Boehringer Mannheim). It was carried out according to the instructions provided by the manufacturer. One microliter of each of the 4 dNTPs $(10 \mathrm{mM}$ each dNTP (MBI Fermentas, Vilnius, Lithuania), final concentration $0.2 \mathrm{mM}$ each $\mathrm{dNTP}$ ) and $1 \mu \mathrm{l}$ each of the upstream and downstream primers $(20 \mu \mathrm{M}$ stock, Clontech, USA) and total RNA extract were added to a total reaction volume of $50 \mu \mathrm{l}$. This was overlaid with $50 \mu \mathrm{l}$ mineral oil.

The upstream and downstream primers for IL-1 $\alpha$ were initially purchased from Clontech, USA, and later synthesized from Genset Singapore Biotech Pte. Ltd, Singapore. The primers for $\beta$-actin were synthesized from Genset Singapore Biotech Pte. Ltd, and were used as internal controls throughout the experiments (Weihua et al. 2000). The primers used were: 5'-AAGATGTCCAACTTCACCTTCAAGGAGAGCCG-3' plus 5'-AGGTCGGTCTCACT ACCTGTGATGAGTTTTGG- $3^{\prime}$ for IL- $1 \alpha$; and $5^{\prime}$-GGGCAC AGTGTGGGTGAC-3' plus 5'-CTGGCACCACACCTTCTAA$\mathrm{C}-3^{\prime}$ for $\beta$-actin.

One round of RT was carried out in a thermocycler (MJ Research, Waltham, MA, USA) equilibrated at $50^{\circ} \mathrm{C}$ for $30 \mathrm{~min}$, which was followed by an initial denaturation step at $94^{\circ} \mathrm{C}$ for $2 \mathrm{~min}$. This was followed by 35 cycles of PCR. In each cycle of PCR the denaturation was carried out for $1 \mathrm{~min}$ at $94^{\circ} \mathrm{C}$, annealing was carried out for $1 \mathrm{~min}$ at $60^{\circ} \mathrm{C}$ and elongation was carried out for $2 \mathrm{~min}$ at $68^{\circ} \mathrm{C}$. Finally, the samples were elongated for $7 \mathrm{~min}$ at $68^{\circ} \mathrm{C}$ and then stored at $4{ }^{\circ} \mathrm{C}$ until further use. The RT-PCR products were analyzed by agarose gel $(2 \%)$ electrophoresis. A molecular weight marker (DNA/HindIII digest) was used to approximate the size of the PCR products.

The amplified fragments were purified from the agarose gel using a QIAEX II, Gel extraction kit (Qiagen, Hilden, Germany) and subcloned using the TOPO TA cloning kit
(Invitrogen). These fragments/inserts were then sequenced using SP6 and T7 primers to confirm the PCR products.

\section{Effect of IL-1 $\alpha$ on implantation}

Because several biological effects of LPS are mediated by IL-1, the hypothesis that this cytokine could cause implantation failure in the mouse was tested. A single dose of $100 \mathrm{ng} /$ animal of IL-1 $\alpha$ (BD Biosciences Pharmingen, San Diego, CA, USA) was given i.p. to four pregnant females on day 1 of pregnancy. The control animals $(n=3)$ were injected with an equal volume $(200 \mu \mathrm{l})$ of the vehicle (PBS). The status of implantation was evaluated by performing a pontamine blue dye test in all the animals on day 5 of pregnancy.

\section{Statistical analyses}

Statistical analyses were performed using one-way analysis of variance (ANOVA) with Duncan's multiple range test for comparison of the significance level $(P)$ between control and treated values. A $P<0.05$ value was considered as a significant difference between the values compared.

\section{Results}

\section{Determination of the minimum dose of LPS that induces $100 \%$ embryonic loss}

The status of pregnancy for the animals treated with 1,2 , 4, 5, 10 or $50 \mu \mathrm{g}$ LPS/animal was evaluated by visual examination of the uterine horns and individual gestational sacs on day 14 of pregnancy. The minimum dose that induced $100 \%$ embryonic loss in the mouse when given on day 0.5 of pregnancy was found to be $5 \mu \mathrm{g}$ LPS/mouse (i.e. $250 \mu \mathrm{g}$ LPS/kg body weight). This was considered as the minimum dose (MD) of LPS required for inducing complete $(100 \%)$ embryonic loss.

No pontamine blue-positive sites were observed on day 5 of pregnancy in the uterine horns of pregnant animals treated on day 0.5 with the MD of LPS (Fig. 1).

The minimum dose of LPS-induced inhibition of implantation of blastocysts was found to be significant as compared with that of the control $(P<0.05$, Table 1$)$. The inhibition of implantation of blastocysts by lower doses of LPS was also found to be significant as compared with that of the control and the minimum dose of LPS $(P<0.05$, Table 1$)$.

\section{Histopathological analysis of reproductive organs of pregnant animals treated with different doses of LPS on day 0.5 of pregnancy}

\section{Uterus}

The histopathological examination of the uterus and ectoplacental cones (EPCs) from animals treated with $2 \mu \mathrm{g}$ LPS/mouse did not show any considerable alterations as 


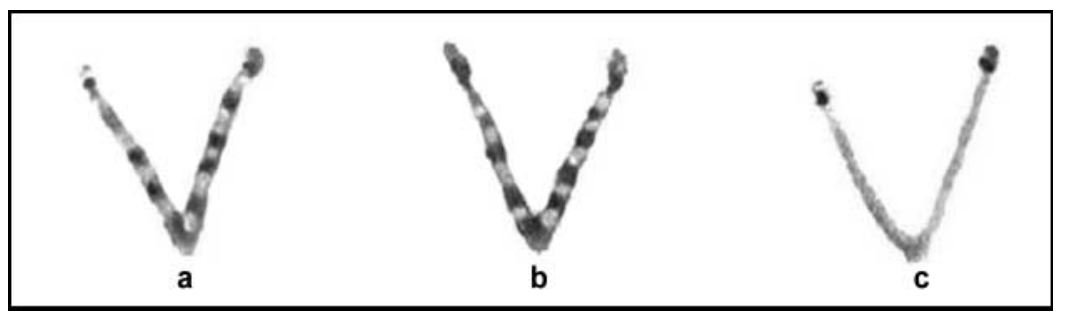

Figure 1 Photographs of uterine horns showing the effect of the minimum dose (MD) of LPS on implantation of blastocysts when administered on day 0.5 of pregnancy. Panels (a), (b) and (c) show the status of implantation in uterine horns (as observed by the pontamine blue test on day 5 of pregnancy) from animals treated with (a) vehicle, (b) lower dose ( $2 \mu \mathrm{g}$ LPS/animal) and (c) the MD ( $5 \mu \mathrm{g} / \mathrm{animal})$ of LPS on day 0.5 of pregnancy. (a) and (b) show pontamine blue positive sites while no pontamine blue positive sites are seen in (c).

Table 1 Effect of different concentrations of LPS on blastocyst implantation.

\begin{tabular}{lcccc}
\hline Group no. & Treatment $(\mu \mathrm{g}$ LPS/animal)* & No. of animals used & No. of implants observed & \% Inhibition of blastocyst implantation \\
\hline 1 & Control & 8 & 72 & $0^{\mathrm{a}}$ \\
2 & 1 & 8 & 34 & $52^{\mathrm{b}}$ \\
3 & 2 & 8 & 31 & $56^{\mathrm{bc}}$ \\
4 & 4 & 8 & 10 & $86^{\mathrm{cd}}$ \\
5 & 5 & 8 & Nil & $100^{\mathrm{d}}$ \\
6 & 10 & 8 & Nil & $100^{\mathrm{d}}$ \\
7 & 50 & 8 & Nil & $100^{\mathrm{d}}$ \\
\hline
\end{tabular}

* LPS was administered intraperitoneally (i.p.) to pregnant animals on day 0.5 of pregnancy.

Values with different superscripts differ from each other at $P \leq 0.05$ (based on Duncan's multiple range test).

compared with those of controls on day 14 of pregnancy (Fig. 2a and b).

The higher doses of LPS (i.e. 3 and $4 \mu \mathrm{g}$ LPS/mouse) showed degenerated embryos, reduced deciduas and ectoplacental cone areas and a large infiltration of macrophages in EPCs on the same day of pregnancy as compared with that of the respective control (Fig. 2a, c, and d). The primary and secondary giant trophoblast cells were also not observed. The visceral yolk sac and Richert's membrane were morphologically indistinct as compared with the control (Fig. 2a, c and d).

The cross-sections of uterine horns from animals treated with the MD of LPS on day 0.5 of pregnancy showed uterine lumen closure, hyperplasia of the luminal epithelium, degenerated glands, absence of mitotic bodies and a large number of macrophages in oedematose stroma on day 14 of pregnancy (Fig. 2a and e) as compared with that of the respective control. The cross-sections of uterine horns from control animals showed normal EPCs and fetuses on the same day of pregnancy (Fig. 2e).

\section{Ovaries}

The ovarian sections from the control animals on day 14 of pregnancy showed well-developed corpora lutea $(\mathrm{CL})$ with clear, large and vacuolated cells at the center, mitotic bodies ( $\sim 3$ per 100 nuclei) and macrophages ( $\sim 10$ per $40 \times$ view field of the microscope) (Fig. 3a). Ovarian sections from animals treated with the MD of LPS showed shrunken cells at the center with indistinct cell boundaries and a greater number of mitotic bodies $(\sim 5$ per 100 nuclei) and macrophages ( $\sim 15$ per $40 \times$ view field of the microscope) as compared with that of the control (Fig. 3a and e). Signs of stromal cell infiltration were also recorded. However, the ovarian sections from animals treated with the lower doses of LPS (i.e. 2, 3, and $4 \mu \mathrm{g}$ LPS/animal) did not show regression of $\mathrm{CL}$ as compared with that of the respective control (Fig. 3a, b, c and d).

\section{Effect of LPS on expression of IL-1a in embryos collected at different stages of the preimplantation period of pregnancy}

In the present study, 500 embryos recovered during different stages of the preimplantation period (i.e. on days 1.5, $2.5,3.5,4.0,4.125,4.33$ and 4.42) of pregnancy from control and LPS-treated animals were used at each time point to study the expression of proinflammatory cytokines and growth factors (e.g., IL- $1 \alpha$, IL- $1 \beta$, TNF- $\alpha$, and Colony Stimulating Factor-1 (CSF-1)/M-CSF) by RT-PCR. The expression of $\beta$-actin gene was used as an internal standard throughout the experiments. IL- $1 \alpha$ was expressed in embryos collected from control animals from the 2-cell to the blastocyst stage (i.e. from day 1.5 to day 4.125 of the gestation period) of development (Fig. 4a). However, a delay in its expression was observed in embryos collected from LPS-treated animals. Its expression was observed from day 4.3 of pregnancy until implantation in embryos collected from LPS-treated animals (Fig. 4b). A uniform expression of $\beta$-actin gene was obtained in the embryos 

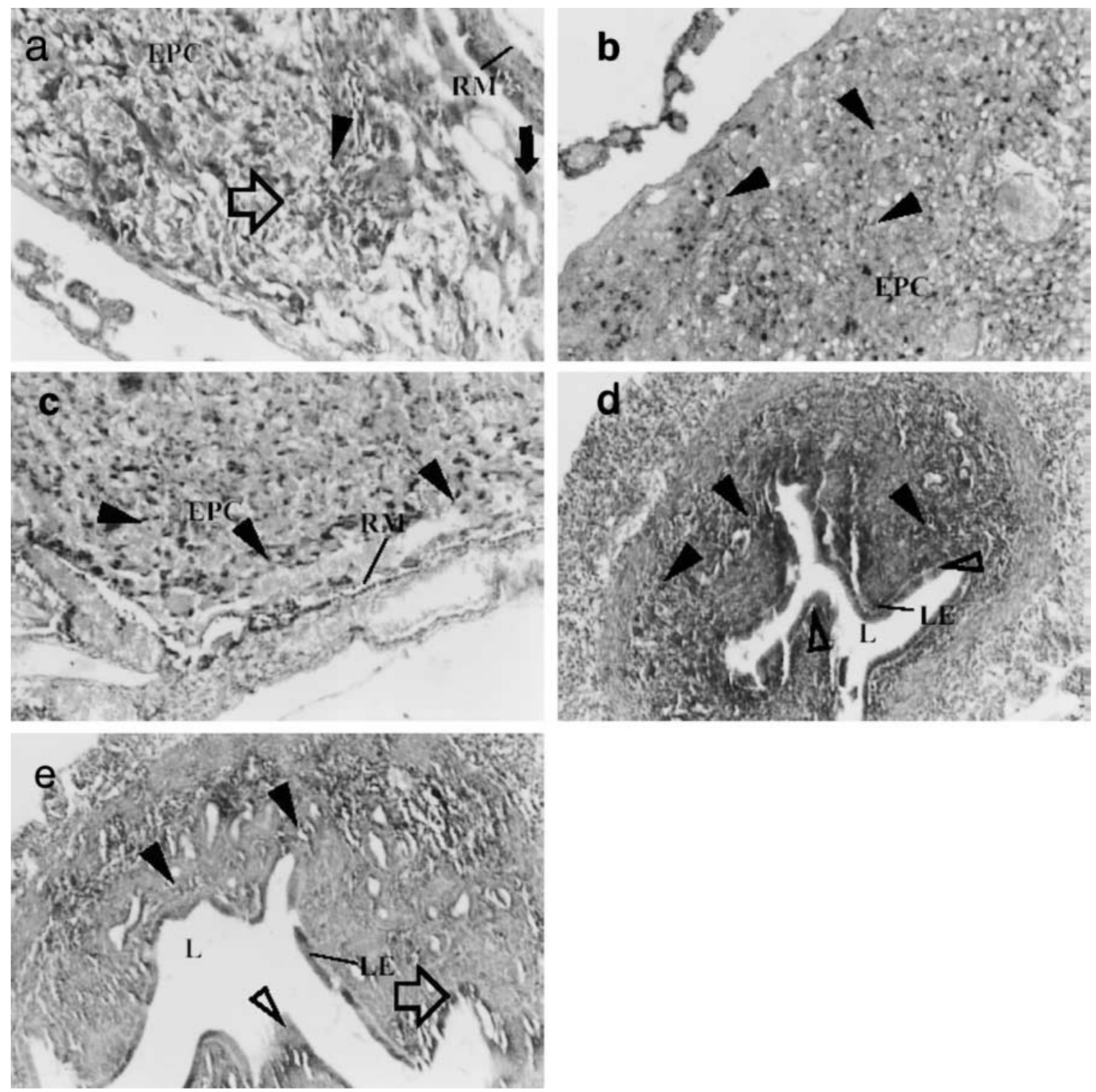

Figure 2 Cross-sections of uterine horns on day 14 of pregnancy from control animals and from animals treated with different doses of LPS on day 0.5 of pregnancy. Note ectoplacental cone (EPC), Reichert's membrane (RM), lumen (L), luminal epithelium (LE), spongiotrophoblast cells (open arrows), secondary trophoblast giant cells (solid arrows), macrophages (solid arrow heads), and hyperplasia (open arrow heads). Panel (a) shows a cross-section of the uterine horn from a control animal (injected with vehicle). Panels (b), (c), (d) and (e) show cross-sections of uterine horns from animals treated with $2 \mu \mathrm{g}, 3 \mu \mathrm{g}, 4 \mu \mathrm{g}$ and $5 \mu \mathrm{g}$ LPS/animal respectively. Magnification $\times 100$.

collected from control and LPS-treated animals during different developmental stages of pregnancy (Fig. 4c).

\section{Effect of LPS on the expression of IL-1 $\alpha$ in uteri collected at different stages of the preimplantation period of pregnancy}

The uterine horns collected from control and LPS-treated animals during different stages of the preimplantation period of pregnancy (i.e. days 1.5, 2.5, 3.5, 4.0, 4.125, 4.33 and 4.42 of pregnancy) were used to study the expression of the proinflammatory cytokine IL- $1 \alpha$ by RTPCR. The expression of $\beta$-actin gene was used as an internal standard throughout the experiments. A uniform level of IL-1 $\alpha$ mRNA was observed during different stages of the preimplantation period of pregnancy (i.e. day 1.54.42 of pregnancy) in uteri collected from control animals. However, its expression increases in uteri collected from LPS-treated animals from day 4.25 of pregnancy until implantation as compared with that of the control (Fig. 5a, b). A uniform expression of $\beta$-actin gene was 

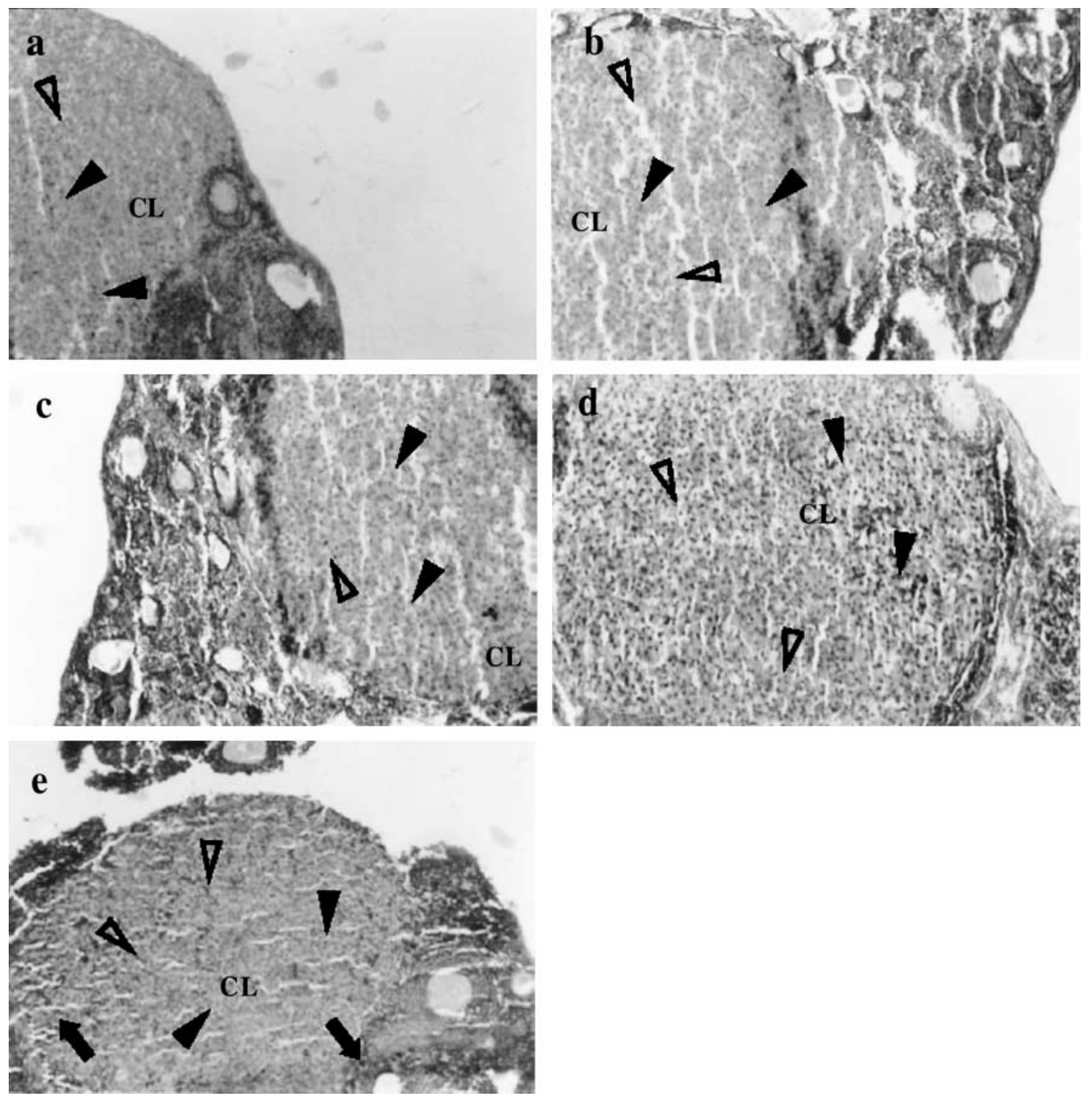

Figure 3 Cross-sections of ovaries on day 14 of pregnancy from control animals and from animals treated with different doses of LPS on day 0.5 of pregnancy. Note corpus luteum $(\mathrm{CL})$, apoptotic/picnotic nuclei (open arrow heads), macrophages (solid arrow heads), and stromal cell infiltration (solid arrows). Panel (a) shows a cross-section of an ovary from a control animal (injected with vehicle). Panels (b), (c), (d) and (e) show cross-sections of ovaries from animals treated with $2 \mu \mathrm{g}, 3 \mu \mathrm{g}, 4 \mu \mathrm{g}$ and $5 \mu \mathrm{g}$ LPS/animal respectively. Magnification $\times 100$.

obtained in the uteri collected from control and LPS-treated animals during different developmental stages of pregnancy (Fig. 5c).

\section{Effect of IL-1 $\alpha$ on implantation}

The status of pregnancy or the initiation of implantation in IL- $1 \alpha$-treated and control females was checked on day 5 by performing a pontamine blue dye test. No pontamine blue dye positive sites were observed in the uterine horns of the animals treated with the recombinant mouse IL- $1 \alpha$. The control animals, however, showed a normal pattern of implantation, with an average count of nine pontamine blue positive bands per animal.

\section{Discussion}

Low-grade chronic pelvic infections may be a major cause of infertility. Endotoxin-induced pregnancy losses associated with embryonic death, abortion, preterm labor and delivery have been documented in a number of species (Edqvist et al. 1984, Fredriksson et al. 1986, Giri et al. 1990, Schlafer et al. 1994). However, the mechanism of LPS-induced abortion is poorly understood. Abortions in pregnant rodents following endotoxin administration are accompanied by severe damage to the placenta and endometrium (Shalaby et al. 1989, Silen et al. 1989). This indicates that understanding the morphological and molecular events underlying the development and maintenance of a 

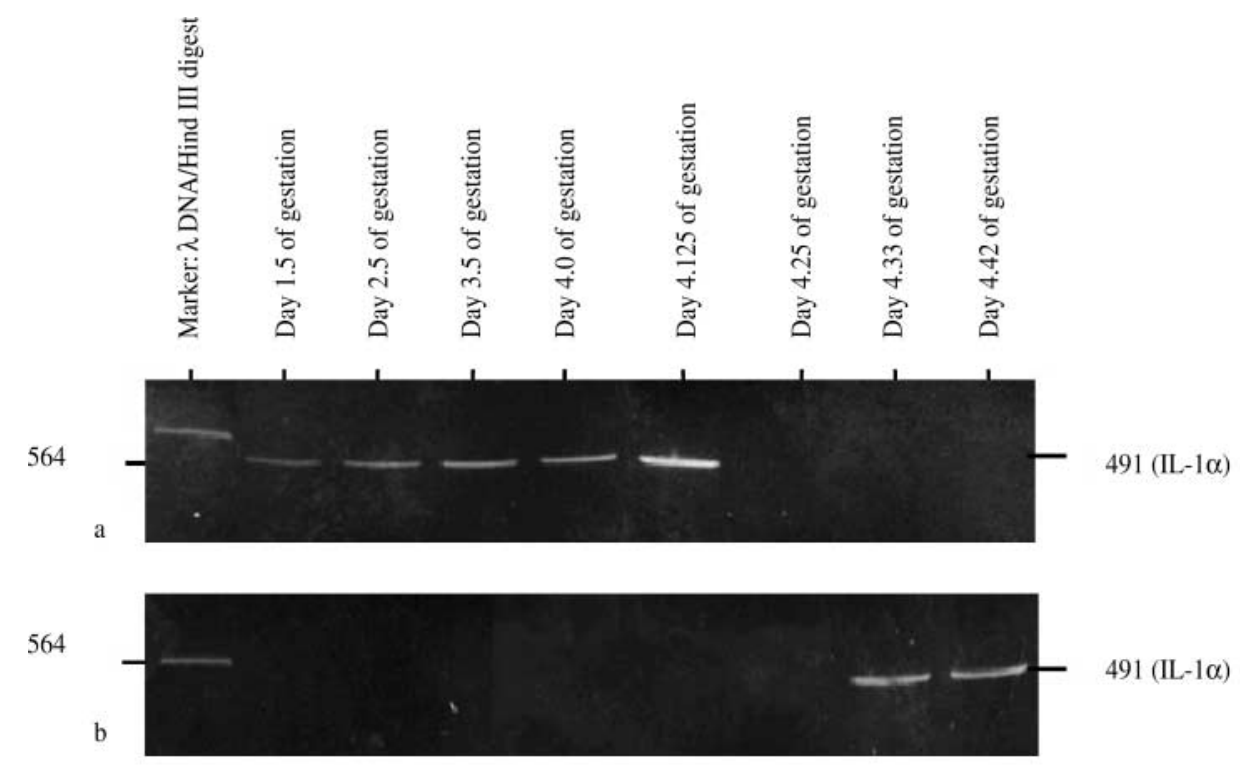

Figure 4 Detection of IL-1 $\alpha$ mRNA transcripts in the preimplantation mouse embryos collected from (a) control and (b) LPS-treated animals at different stages of the preimplantation period of pregnancy by RT-PCR. Panel (c) shows the expression of 125

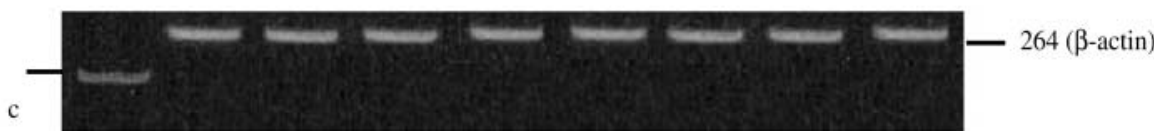
$\beta$-actin.
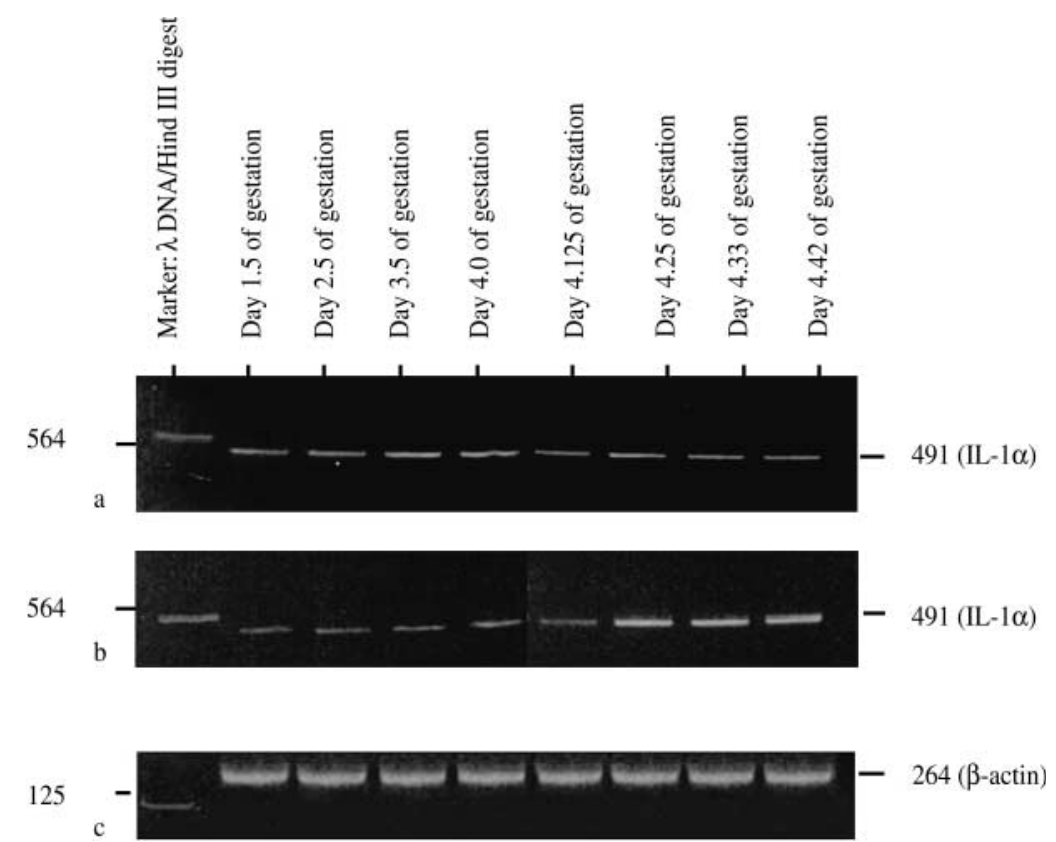

Figure 5 Detection of IL- $1 \alpha$ mRNA transcripts in the preimplantation mouse uterus collected from (a) control and (b) LPS-treated animals at different stages of the preimplantation period of pregnancy by RT-PCR. Panel (c) shows the expression of $\beta$-actin.

receptive uterus may help in the treatment of infertility in humans.

\section{Determination of the minimum effective dose of LPS that induces $100 \%$ embryonic loss}

In the present study, we have clearly demonstrated that $5 \mu \mathrm{g}$ LPS (i.e. $250 \mu \mathrm{g} / \mathrm{kg}$ body weight), when given through the i.p. route to pregnant animals on day 0.5 of pregnancy leads to complete inhibition of implantation. This may be due to a maternal response to LPS that may lead to preimplantation embryonic losses (Silver et al. 1997, Athanassakis et al. 1999). It has been reported that the cells of the reproductive organs produce a wide variety of factors that may regulate the activities of lymphocytes in vitro and such factors may also influence the feto-maternal immunological interactions in vivo. A number of leukocytes, including T-lymphocytes and macrophages, are present at the time of normal implantation in the endometrium and decidua. These cells are responsible for inducing inflammation at the site of implantation 
(Chantakru et al. 2002). The success of implantation depends on such an inflammatory response and any disturbance at this level may lead to embryonic loss.

\section{Histopathological analysis of reproductive organs of pregnant animals treated with different doses of LPS on day 0.5 of pregnancy}

The minimum dose of LPS may alter the normal uterine physiology required for successful implantation of blastocysts in the mouse. Such changes in uterine receptivity for implanting blastocysts may be one of the causes of poor pregnancy outcome. The observed pathophysiology of the uterus in response to the MD of LPS may be due either to a block in the progression of the uterus from the prereceptive phase to the receptive phase or to its conversion from the prereceptive phase to a non-receptive one. The MD of LPS also results in a marked increase in infiltration of macrophages in the uterine stroma, decidua, and the glandular and luminal epithelium on day 14 of pregnancy. The increase in the number of activated lymphocytes and macrophages in response to the MD of LPS during the preimplantation period of pregnancy in the reproductive tissues may also adversely affect the embryonic development and trophoblast proliferation during the early stages of pregnancy, and fetal growth during its later stages in the mouse (Hill et al. 1987). The observed fetal rejection during the early stages of pregnancy in response to LPS may be due to embryotoxic factors produced by activated lymphocytes and macrophages. Thus, in LPS-induced implantation failure, the embryo may be killed as an innocent bystander to the activated leukocytes in response to bacterial endotoxins.

\section{Effect of LPS on the expression of IL-1 $\alpha$ in preimplantation embryos and uterus: role of IL-1 $\alpha$ in implantation failure}

The interleukin-1 system (i.e. IL-1 $\alpha$, IL-1 $\beta$, and IL-1 receptor (IL-1R)) has previously been shown to play an important role in the development of murine preimplantation embryos (Kauma 2000). The positive expression of IL- $1 \alpha$ and some matrix metalloproteinases (MMPs) occurs in embryos until implantation, and may be required for the early embryonic development and for the invasion of trophoblasts in the mouse (Sharkey et al. 1996, Bischop et al. 2000). Takacs and Kauma (1996) reported the presence of IL-1 $\beta$ in the preimplantation embryos; however, they could not find IL- $1 \alpha$ expression in the mouse embryos. Expression of IL- $1 \alpha$ in the mouse blastocysts recovered from normal animals during implantation has been reported previously (Basak et al. 2002) suggesting its role in implantation.

It has been suggested that the embryonic IL-1 system upregulates the endometrial epithelial $\beta_{3}$ intigrin (Simon et al. 1998), which enhances the ability of the implanting blastocyst to adhere to the endometrial-epithelial cell (EEC) monolayers (Simon et al. 1997). Our observations indicate that IL-1 $\alpha$ is expressed only during the early stages of development. The embryonic expression of either of the two forms of IL-1 throughout the preimplantation period of pregnancy may be necessary to ensure an uninterrupted and upregulated expression of the $\beta_{3}$ integrins and various other genes necessary to maintain the uterus in a receptive state.

In a previous study, the expression of IL-1 receptor was not detected in the embryos of the mouse at any stage of the preimplantation period of pregnancy; however, the expression of IL-1 receptor type I (IL-1RI) was observed in the uterus of pregnant animals during this stage of pregnancy (Tackacs \& Kauma 1996). This result indicates that the embryos at the early/preimplantation period of pregnancy may not be capable of responding to IL-1; however, embryonic IL-1 may potentially signal the maternal endometrium through the IL-1RI. The altered pattern of expression of embryonic IL-1 gene and LPS itself may initiate a cascade of additional proinflammatory events which may contribute to infection-mediated pregnancy losses (Gibbs \& Duff 1991, Silver et al. 1994) in the mouse.

IL-1 is known to be produced by decidual cells in response to LPS and is present in the amniotic fluid of women with preterm labor and intra-amniotic infection (Romero et al. 1989). In the present study, we found that IL-1 $\alpha$ is expressed in the uterus throughout the preimplantation period of pregnancy. Simon et al. (1996) suggested that the secretion of IL- $1 \alpha$ and IL-1 $\beta$ into the endometrial cavity mimics the levels of steroid hormones, with IL-1 $\beta$ reaching its peak at the time of implantation. We observed a similar trend and pattern in the expression of IL- $1 \alpha$ and IL-1 $\beta$ in the uterus of control/normal animals (K Deb, unpublished data). We observed an increase in the expression of IL-1 $\alpha$ in the uterus of LPS-treated animals from day 4.25 of pregnancy until implantation as compared with that of the respective controls. It has been reported previously that the exogenously administered IL$1 \alpha$ can cause fetal death, and in some cases abortion, in pregnant mice (Silen et al. 1989, Romero et al. 1991). In this study, we found that exogenously administered IL- $1 \alpha$ could cause failure in the initiation of implantation. The intraperitoneal injection of $100 \mathrm{ng}$ recombinant mouse IL- $1 \alpha$ on day 1 of pregnancy caused $100 \%$ failure in blastocyst implantation. This dose of IL- $1 \alpha$ has also been shown previously to mimic the behavioral responses induced by 0.5 to $5 \mu \mathrm{g}$ LPS per mouse (Dunn \& Swiergiel 1998). These results indicate that elevated levels of IL-1 $\alpha$ in response to LPS could be responsible for infertility in the mouse.

It has been suggested that many of the biological effects of IL-1 are mediated through prostaglandins (Dinarello \& Wolf 1993) and that IL-1 causes prostaglandin (PG) production by gestational tissues in vitro (Romero et al. 1989). However, Silver et al. (1997) reported that lipopolysaccharide-induced fetal death is a prostaglandin-independent effect. Dudley et al. (1993) observed that IL-1 $\beta$ and 
LPS significantly increase the production of $\mathrm{PGE}_{2}$ and IL-6 from murine decidua. We observed an upregulated expression of IL-1 $\beta$ gene in the uterus of LPS-treated animals throughout the preimplantation period of pregnancy as compared with that of the respective controls (K Deb, unpublished data). Our observations indicate that endotoxin-induced implantation failure may be due to a combined effect of LPS and the elevated levels of both forms of IL-1, which may trigger the production of prostaglandins and other cytokines (e.g. TNF, IL-6, and IL-8) by the gestational tissues.

The altered pattern of expression of both forms of IL-1 in embryos and its upregulation in the uterus during the preimplantation period of pregnancy in response to LPS may stimulate the expression of COX-2 gene and the synthesis of $\mathrm{PGE}_{2}$ in the endometrial stromal and epithelial cells (Bany \& Kennedy 1995, Ishihara et al. 1995). Psychoyos et al. (1995) suggested that PG-mediated inflammatory reaction in the endometrium in response to the implanting embryo is necessary for implantation. Jacobs et al. (1994) reported that newly differentiated luminal epithelial cells at the implantation site express COX-2. Regulation of the expression of COX-2 gene is the key control of PG synthesis and any alterations in the level of COX-2 may lead to an alteration in the biosynthesis of $\mathrm{PGE}_{2}$. Thus, based on these observations, we propose that the controlled expression of IL- 1 in embryonic and uterine tissue may be essential for the successful implantation of embryos in the mouse, and any disturbance in the level and/or pattern of expression of this cytokine in response to LPS may lead to failure of implantation through a PG-dependent pathway.

The administration of bacterial endotoxin may result in the regression of the $\mathrm{CL}$ and inhibition of steroidogenesis (Taylor \& Terranova 1996). Thus any disturbance at the level of the progesterone/estrogen ratio in the mother may lead to an unsuccessful pregnancy outcome. Terranova and Mongomery-Rice (1997) reported that LPS may directly trigger the expression of proinflammatory cytokines (i.e. IL1, IL-6. and TNF) from the luteal cells in vitro. The rise in the levels of proinflammatory cytokines, directly or indirectly, may disturb the delicate inflammatory reactions at the feto-maternal interface during blastocyst implantation and may also disturb the delicate immune balance in pregnant animals, which may eventually lead to failure of implantation and pregnancy loss. LPS is also known to be a potent stimulator of nitric oxide (NO) which is known to play an important role during pregnancy and implantation. LPS-induced high levels of uterine NO production has been reported to cause $100 \%$ embryonic resorption at $24 \mathrm{~h}$, with complete fetus expulsions at $48 \mathrm{~h}$ (Ogando et al. 2003). Thus, LPS seems to disturb the normal level and distribution of a number of factors of embryonal or maternal origin which are responsible for the development of endometrial receptivity. The effect of the minimum effective dose of LPS on the expression of various cytotoxic factors and the normal development and differentiation of preimplantation embryos in vivo is currently being evaluated in our laboratory. Understanding the exact role of these factors in embryo implantation and in endotoxinmediated pregnancy loss may help not only in the development of novel therapeutic interventions but also in developing new strategies for improving the success of reproductive technologies and for the development of new contraceptives for women.

\section{Acknowledgements}

We thank the All India Council For Technical Education (AICTE), New Delhi, India, The Rockefeller Foundation, New York, USA for financial support and the Council for Scientific and Industrial Research (CSIR), New Delhi, India for a Senior Research Fellowship to K D. We are grateful to Dr S C Pant, Toxiocology Division, DRDE, Gwalior, India, Dr P L Pakrashi, CAS in Zoology, Banaras Hindu University, Varanasi, India and Prof. Ashok K Jain, SOS in Botany, Jiwaji University, Gwalior, India for their valuable technical help.

\section{References}

Arici A, Engin O, Attar E \& Olive DL 1995 Modulation of leukemia inhibitory factor gene expression and protein biosynthesis in human endometrium. Journal of Clinical Endocrinology and Metabolism 80 1908-1915.

Athanassakis I, Farmakiotis V \& Papadimitriou L 1999 Uterine cytokine production during the menstrual cycle and preimplantation stages in mice. Developmental Immunology 7 33-42.

Bagavandoss P, Wiggins RC, Kunkel SL, Remick DG \& Keyes PL 1990 Tumor necrosis factor production and accumulation of inflammatory cells in the corpus luteum of pseudopregnancy and pregnancy in rabbits. Biology of Reproduction 42 367-376.

Baines MG, Duclos AJ, de Fougerolles AR \& Gendron RL 1996 Immunological prevention of spontaneous early embryo resorption is mediated by nonspecific immunostimulation. American Journal of Reproductive Immunology 35 34-42.

Bany BM \& Kennedy TG 1995 Interleukin-1 alpha regulates prostaglandin production and cyclooxygenase activity in sensitized rat endometrial stromal cells in vitro. Biology of Reproduction 53 $126-132$.

Basak S, Dubanchet S, Zourbas S, Chaouat G \& Das C 2002 Expression of pro-inflammatory cytokines in mouse blastocysts during implantation: modulation by steroid hormones. American Journal of Reproductive Immunology 47 2-11.

Ben-Rafael Z \& Orvieto R 1992 Cytokines involvement in reproduction. Fertility and Sterility 58 1093-1099.

Bischop P, Meisser A \& Campana A 2000 Mechanism of endometrial control of trophoblast invasion. Journal of Reproduction and Fertility Supplement 55 65-71.

Burell R 1994 Human responses to bacterial endotoxin. Circulatory Shock 43 137-153.

Chantakru S, Miller C, Roach LE, Kuziel WA, Maeda N, Wang WC, Evans SS \& Croy BA 2002 Contributions for self-renewal and trafficking to the uterine NK cell population of early pregnancy. Journal of Immunology 168 22-28.

Chomczynski P \& Sacchi N 1987 Single-step method of RNA isolation by acid guanidium thiocyanate-phenol-chloroform extraction. Analytical Biochemistry 162 156-159.

Cram LF, Zapata MI, Toy EC \& Baker B 3rd 2002 Genitourinary infections and their association with preterm labor. American Family Physician 65 241-248.

Dinarello CA \& Wolff SM 1993 The role of interleukin-1 in disease. New England Journal of Medicine 328 106-113. 
Dudley DJ, Chen CL, Branch DW, Hammond E \& Mitchell MD 1993 A murine model of preterm labor: inflammatory mediators regulate the production of prostaglandin $E_{2}$ and Interleukin- 6 by murine decidua. Biology of Reproduction 48 33-39.

Dunn AJ \& Swiergiel AH 1998 The role of cytokines in infection related behavior. Annals of the New York Academy of Sciences 840 577-585.

Edqvist L, Fredriksson G \& Kindahl H 1984 Some aspects of endotoxins and corpus luteum function in ruminants. In Panel Proceedings of Nuclear Techniques in Tropical Animal Diseases, pp 57-68. Vienna, Australia: International Atomic Energy Agency.

Finn CA \& McLaren A 1967 A study of the early stages of implantation in mice. Journal of Reproduction and Fertility 13 259-267.

Finn CA, Pope M \& Milligam SR 1995 Control of uterine stromal mitosis in relation to uterine sensitivity and decidualization in mice. Journal of Reproduction and Fertility 103 153-158.

Fredriksson G, Kindahl H \& Stabenfeldt G 1986 Endotoxin-induced and prostaglandin-mediated effects on the corpus luteum in the mare. Theriogenology 25 309-316.

Gibbs RS \& Duff P 1991 Progress in pathogenesis and management of clinical intra-amniotic infection. American Journal of Obstetrics and Gynecology 164 1317-1326.

Giri SN, Stabenfeldt GH, Bruss MI, BonDurant RH \& Osburn BI 1990 Effect of endotoxins on circulating levels of eicosanoids, progesterone, cortisol, glucose, and lactic acid, and abortion in pregnant cows. Veterinary Microbiology 21 211-231.

Hill JA, Haimovici F \& Anderson DJ 1987 Products of activated lymphocytes and macrophages inhibit mouse embryo development in vitro. Journal of Immunology 139 2250-2254.

Huet-Hudson YM \& Dey SK 1990 Requirement for progesteronepriming and its long term effect on implantation in the mouse. Proceedings of the Society for Experimental Biology and Medicine $193259-263$.

Ishihara O, Matsuoka K, Kinoshita K, Sullivan MH \& Elder MG 1995 Interleukin -1 beta-stimulated $\mathrm{PGE}_{2}$ production from early first trimester human decidual cells is inhibited by dexamethasone and progesterone. Prostaglandins 49 15-26.

Jacobs AL, Hwang D, Julian J \& Carson DD 1994 Regulated expression of prostaglandin endoperoxide synthase-2 by uterine stroma. Endocrinology 135 1807-1815.

Kauma SW 2000 Cytokines in implantation. Journal of Reproduction and Fertility Supplement 55 31-42.

Mizuno D \& Soma GI 1988 Endogeneous and exogeneous TNF therapy (EET therapy): conceptual and experimental grounds. Annales de I'Institut Pasteur Immunologie 139 282-285.

Ogando DG, Paz D, Cella M \& Franchi AM 2003 The fundamental role of increased production of nitric oxide in lipopolysaccharideinduced embryonic resorption in mice. Reproduction 125 95-110.

Paria BC, Lim H, Das SK, Reese J \& Dey SK 2000 Molecular signaling in uterine receptivity for implantation. Seminars in Cell and Development Biology 11 1-8.

Psychoyos A 1973 Endocrine control of egg implantation. In Handbook of Physiology, pp 185-215. Eds RO Greep, EJ Astwood \& SR Geirger. Washington DC: American Physiological Society.

Psychoyos A, Nikas G \& Gravanis A 1995 The role of prostaglandin in blastocyst implantation. Human Reproduction 10 (Suppl 2) 30-42.

Romero R, Duram S, Dinarello CA, Oyarzun E, Hobbins JC \& Mitchell MD 1989 Interleukin-1 stimulates prostaglandin biosynthesis by human amnion. Prostaglandins 37 13-22.

Romero R, Mazor M \& Tartakovsky B 1991 Systemic administration of interleukin-1 induces preterm parturition in mice. American Journal of Obstetrics and Gynecology 165 969-971.
Rupasri A, Shivkumar KR, Sreenath BR \& Seshagiri PB 1995 Assessment of developmental retardation and abnormality of in vivo produced preimplantation embryos in rat. Indian Journal of Experimental Biology 33 911-916.

Schlafer DH, Yuh B, Foley GL, Elssaser TH, Sadowsky D \& Nathanielsz PW 1994 Effect of Salmonella endotoxin administered to the pregnant sheep at 133-142 days gestation on fetal oxygenation, maternal and fetal adrenocorticotropic hormone and cortisol, and maternal plasma tumor necrosis factor $\alpha$ concentrations. Biology of Reproduction 50 1297-1302.

Shalaby MR, Laegreid WW, Ammann AJ \& Liggitt HD 1989 Tumor necrosis factor $-\alpha$ associated uterine endothelial injury in vivo. Influence of dietary fat. Laboratory Investigation 61 564-570.

Sharkey ME, Adler RR, Brenner CA \& Nieder GL 1996 Matrix metalloproteinase expression during mouse peri-implantation development. American Journal of Reproductive Immunology $\mathbf{3 6}$ $72-80$.

Silen ML, Firpo A, Morgello S, Lowry SF \& Francus T 1989 Interleukin- and tumor necrosis factor- $\alpha$ cause placental injury in rat. American Journal of Pathology 135 239-244.

Silver RM, Lohner WS, Daynes RA, Mitchell MD \& Branch DW 1994 Lipopolysaccharide induced fetal death: the role of TNF alpha. Biology of Reproduction 50 1108-1112.

Silver RM, Edwin SS, Umar F, Dudley DJ, Branch DW \& Mitchell MD 1997 Bacterial lipopolysaccharide mediated murine fetal death: the role of interleukin-1. American Journal of Obstetrics and Gynecology 176 544-549.

Simon C, Gimeno MJ, Marcader A, Frances A, Velasco JG, Remohi J, Polan ML \& Pellicer A 1996 Cytokines adhesion molecules-invasive proteinases. The misssing paracrine/autocrine line in embryonic implantation. Molecular Human Reproduction 6 405-424.

Simon C, Gimeno MJ, Marcader A, O'Connor JE, Remohi J, Polan ML \& Pellicer A 1997 Embryonic regulation of integrins $\beta 3, \alpha 1$ and $\alpha 4$ on human endometrial epithelial cells. Journal of Clinical Endocrinology and Metabolism 82 2607-2616.

Simon C, Moreno C, Remohi J \& Pellicer A 1998 Cytokines and embryo implantation. Journal of Reproductive Immunology 39 117-131.

Strus M, Malinowska M \& Heczko PB 2002 In vitro antagonistic effect of Lactobacillus on organisms associated with bacterial vaginosis. Journal of Reproductive Medicine 47 41-46.

Takacs P \& Kauma S 1996 The expression of interleukin-1 alpha, interleukin-1 beta, and IL-1 receptor type 1 mRNA during preimplantation mouse development. Journal of Reproductive Immunology 32 27-35.

Taylor CC \& Terranova PF 1996 Lipopolysaccharide inhibits in vitro luteinizing hormone-stimulated rat ovarian granulosa cell estradiol but not progesterone secretion. Biology of Reproduction $\mathbf{5 4}$ 1390-1396.

Terranova PF \& Mongomery-Rice V 1997 Review: cytokine involvement in ovarian processes. American Journal of Reproductive Immunology 37 50-63.

Weihua Z, Saji S, Makinen S, Cheng G, Jensen EV, Warner M \& Gustafsson JA 2000 Estrogen receptor $(E R) \beta$, a modulator of ER $\alpha$ in the uterus. PNAS 97 5936-5941.

Received 17 November 2003

First decision 12 February 2004

Accepted 23 March 2004 